\title{
Retrospective Study of Managing Group A and B Retinoblastoma
}

\author{
MAGDY M. ELBARBARY, M.D.; HISHAM M. KHAIRY ABDELDAYEM, M.D.; \\ AHMED M. HABIB, M.D. and ABDELRAHMAN M.Sh. YOUSSEF, M.Sc.
}

The Department of Ophthalmology, Faculty of Medicine, Ain Shams University

\begin{abstract}
Background: Retinoblastoma is the most common intraocular tumor in children. There are two forms heritable and nonheritable. Leukocoria is the most common presenting sign, accounting for about $56.1 \%$ of cases. Strabismus is the second most common mode of presentation. Early retinoblastoma patients (group A and B ICRB) treated by systemic chemotherapy in conjunction with local control have the higher rate of eye salvage.

Aim of Study: To classify retinoblastoma patients presented to Oncology Unit of Ain Shams Department of Ophthalmology to international groups and study presentation, modalities of treatment and treatment outcome of group A and B patients. To see to what extent in Ain Shams Department of Ophthalmology we succeed achieving eye salvage in early retinoblastoma patients group $\mathrm{A}$ and $\mathrm{B}$.
\end{abstract}

Patients and Methods: This study involved patients have been treated at Oncology Unit of Ain Shams Department of Ophthalmology. Data was extracted from recorded files of patients in the period from January 2004 till January 2012. All patients data were subjected to refinement of: Age, sex, date of first visit, complaint, family history, fundus examination, diagnosis, classification to international groups, treatment, follow-up.

Results: Complete tumor regression had occurred in $90 \%$ of all group A and B patients following treatment with systemic chemotherapy plus focal laser thermotherapy. Enucleation was needed in $6.7 \%$ of all patients. Group A only patients had a $90 \%$ percentage of complete tumor regression, with only one patient died from pneumonia (one out of 30). Group B only patients had a $90.5 \%$ percentage of complete tumor regression, with only two patients had needed enucleation (2 out of 30). EBR was needed in $6.7 \%$ of all patients. Age at presentation mean was 1.09 year with range (0.1-3). Regarding presenting symptoms, $80 \%$ of patients presented with leukocoria and $13.3 \%$ with squint. Family history was negative in $86.7 \%$ and positive in $13.3 \%$.

Conclusion: Our conclusion is that early retinoblastoma patients (group A and B ICRB) treated by systemic chemotherapy in conjunction with local control have resulted in ocular salvage rates exceeding $90 \%$ for early intraocular disease.

Correspondence to: Dr. Abdelrahman M.Sh. Youssef, The Department of Ophthalmology, Faculty of Medicine, Ain Shams University
Key Words: Retinoblastoma - International classification for intraocular retinoblastoma (ICRB) - Chemoreduction-Laser thermotherapy.

\section{Introduction}

RETINOBLASTOMA is a rare form of cancer that rapidly develops from the immature cells of a retina, the light-detecting tissue of the eye. It is the most common malignant cancer of the eye in children. Though most children survive this cancer, they may lose their vision in the affected eye(s) or need to have the eye removed $[1,2]$.

About 1 out of 3 retinoblastomas is caused by a mutation in the retinoblastoma 1 (RB1) gene (long arm of chromosome 13 band 13q14) that is present in all the cells of the child's body. But of these cases, only about 1 in 4 is inherited from one of the child's parents. In the rest, the gene mutation is not inherited, but occurs during early development in the womb. Most of the remaining 2 out of 3 retinoblastomas occur as a result of a random RB 1 gene mutation that occurs only in one cell of one eye [3].

Intraocularly, it exhibits a variety of growth patterns, endophytic growth occurs when the tumor breaks through the internal limiting membrane and has an ophthalmic appearance of a white-to-cream mass showing either no surface vessels or small irregular tumor vessels, exophytic growth occurs in the subretinal space and is often associated with subretinal fluid accumulation and retinal detachment, diffuse infiltrating growth is a rare subtype comprising $1.5 \%$ of all retinoblastomas characterized by a relatively flat infiltration of the retina by tumor cells but without a discrete tumor mass $[4,5]$

Leukocoria (white pupillary reflex or cat's eye reflex) is the most common presenting sign, accounting for about $56.1 \%$ of cases. Strabismus, 
which occurs as a result of visual loss, is the second most common mode of presentation. Thus, funduscopic examination through a well-dilated pupil must be performed in all cases of childhood strabismus. Other less common signs and symptoms of retinoblastoma include: Vision problems, red painful eye with glaucoma, hyphema, bulging of the eye, Anisocoria, Heterochromia iridis, Orbital cellulitis \& Nystagmus [6].

Patients noted to have signs of retinoblastoma should undergo complete eye examination including an estimation of the patient's visual acuity for both eyes. A dilated fundus examination with indirect ophthalmoscopy should be completed since ancillary diagnostic studies play only a secondary role when the fundus can be visualized clearly. Imaging tests (Imaging tests use X-rays, sound waves, magnetic fields, or radioactive substances to create pictures of the inside of the body) will be done to help confirm it and to find out how far it may have spread within the eye and possibly to other parts of the body [7].

The outlook (prognosis) for children with retinoblastoma depends, to some extent, on the cancer's stage. The stage is also an important factor in choosing treatment. The International Classification for Intraocular Retinoblastoma (ICRB) is the newer retinoblastoma staging system. In this staging system, intraocular retinoblastoma is differentiated into 5 groups, from A to $\mathrm{E}$. A indicates a better prognosis, and $\mathrm{E}$ indicates a poorer prognosis using existing treatment modalities. According to the ICRB, patients within groups $\mathrm{A}, \mathrm{B}$, and $\mathrm{C}$ had a significant chance of ocular salvage and avoidance of EBRT while those within group D had a much higher rate of treatment failure, with approximately one half requiring External Beam Radiation Therapy (EBRT) or enucleation. Group E eyes were intended to be managed with primary enucleation [8-10].

Prior to the International Classification for Intraocular Retinoblastoma, the Reese-Ellsworth classification system was the most useful system when (EBRT) was the standard of treatment for eye salvage. However, now that chemotherapy has supplanted radiation, this classification system is not as predictive of outcome and survival $[8,9]$.

The goals of treatment for retinoblastoma are to preserve the patient's life and salvage the affected globe, to preserve as much vision as possible and to limit the risk of second cancers later in life, which can be caused by treatment, particularly in children with hereditary retinoblastoma [11,12].
Overall, more than 9 in 10 children with retinoblastoma are cured. The chances of long-term survival are much better if the tumor has not spread outside the eye [13].

The main types of treatment for retinoblastoma are chemotherapy, thermotherapy (using a type of laser to apply heat to kill small tumors), photocoagulation (using lasers to kill small tumors or the blood vessels that feed them), Cryotherapy (using cold to freeze and kill small tumors), radiation therapy and surgery (enucleation).

Sometimes more than one type of treatment may be used. The treatment options are based on the extent of the cancer and other factors [14]

Patients with treated retinoblastoma should be monitored with examination under anesthesia every 3-4 months until age 3-4 years, after which they are examined under anesthesia every 6 months until age 5-6 years and then annually thereafter. At about age 8 years, most patients can tolerate a dilated fundus examination in the office without anesthesia and can be examined annually in the office thereafter $[15,16]$

In the developed world, retinoblastoma has one of the best cure rates of all childhood cancers (95$98 \%$ ), with more than nine out of every ten sufferers surviving into adulthood. In the UK, around 40 to 50 new cases are diagnosed each year. Good prognosis depends upon early presentation of the child in health facility. Late presentation of the child in hospital is associated with poor prognosis [17-19]

\section{Aim of the work:}

To classify retinoblastoma patients presented to Oncology Unit of Ain Shams Department of Ophthalmology to international groups and study presentation, modalities of treatment and treatment outcome of group A and B patients. To see to what extent in Ain Shams Department of Ophthalmology we succeed achieving eye salvage in early retinoblastoma patients group A and B.

\section{Patients and Methods}

Type of study: Retrospective observational study.

Study setting: This study involved patients have been treated at Oncology Unit of Ain Shams Department of Ophthalmology.

Study period: Data was extracted from recorded files of patients in the period from January 2004 till January 2012. 


\section{Study population:}

Inclusion criteria: Data extracted from files of all Retinoblastoma patients presented to Oncology Unit of Ain Shams Department of Ophthalmology during study period.

Exclusion criteria: Incomplete patients' data. Examination details not appropriate enough for classification. Lost follow-up. Patients of other groups than $\mathrm{A}$ and $\mathrm{B}$.

Sampling method: Convenience sampling.

Sample size: 30 eyes of 30Pts.

Ethical considerations: Confidentiality of records were considered.

Study procedure: All patients data were subjected to refinement of: Age, sex, date of first visit, complaint, family history, fundus examination, diagnosis, classification to international groups, treatment, follow-up.

Details of dilated fundus examination using cyclopentolate with indirect ophthalmoscopy with scleral indentation documented in patients' files such size and number of tumor and other associated pathology (assessment of the mass color, location, overlying retinal detachment and subretinal fluid, presence of vitreous seeds (focal or diffuse) and determination of its class and subretinal seeds).

\section{Classification to international groups:}

The outlook (prognosis) for children with retinoblastoma depends, to some extent, on the cancer's stage. The stage is also an important factor in choosing treatment. The International Classification for Intraocular Retinoblastoma is the newer retinoblastoma staging system. In this staging system, intraocular retinoblastoma is differentiated into 5 groups, from $\mathrm{A}$ to $\mathrm{E}$. A indicates a better prognosis, and $\mathrm{E}$ indicates a poorer prognosis using existing treatment modalities.

In our study we had 9 group (A) patients and 21 group (B) patients.

Tumor size was $3 \mathrm{~mm}$ or less and was located at least $3 \mathrm{~mm}$ from the foveola and $1.5 \mathrm{~mm}$ from OD in all group (A) patients. In group (B) patients, tumor size was $3 \mathrm{~mm}$ or less in 4 Pts. and more than $3 \mathrm{~mm}$ in $17 \mathrm{Pts}$. Tumor was located at least $3 \mathrm{~mm}$ from the foveola and $1.5 \mathrm{~mm}$ from OD in $8 \mathrm{Pts}$. and near OD or foveola in 13Pts.

Treatment: Primary line treatment was collected from documented data.
For group (A), focal diode laser transpupillary thermotherapy was performed until complete tumor regression plus systemic chemotherapy if needed.

For group (B), systemic chemotherapy \pm focal diode laser transpupillary thermotherapy as needed. Other lines of treatment (external beam radiationEnucleation) was needed only in group (B) in case of primary treatment failure.

Chemotherapy treatment protocol: A sixtreatment cycles of chemoreduction therapy with vincristine $\left(1.5 \mathrm{mg} / \mathrm{m}^{2}\right)$, etoposide $\left(200 \mathrm{mg} / \mathrm{m}^{2}\right)$, and carboplatin $\left(560 \mathrm{mg} / \mathrm{m}^{2}\right)$ was administered and a complete blood profile was obtained at monthly intervals. Eyes that responded to chemoreduction therapy received focal transpupillary thermotherapy.

Thermotherapy was used for retinoblastomas of $3 \mathrm{~mm}$ or less in base diameter and $3 \mathrm{~mm}$ or less in thickness without vitreous seeds located at or posterior to the equator. Occasionally, fish flesh portions of larger diameter retinoblastomas that regressed in a type III manner were treated with thermotherapy using an IRIDEX OcuLight SLx (California, USA) Infrared (810nm) laser system. Treatments were administered in the form of monthly cycles, with chemotherapy administered on the first 2-3 days of every month. The laser was set at a continuous mode with a spot diameter ranging from 0.5 to $1.2 \mathrm{~mm}$ and the power was adjusted at $300-400 \mathrm{~mW}$ and was applied for $1-5 \mathrm{~min}$ per spot till covering $100 \%$ of tumor area, the end point was a gentle, light gray color change within the tumor without causing vascular spasm or rapid tumor whitening.

Non regressed tumors were treated with additional chemoreduction and focal treatment. When these methods failed, EBRT (a dose ranging from 35.0 to $45.0 \mathrm{~Gy}$ ) was administered.

\section{Follow-up visits:}

The patients were followed-up under anesthesia by fundus examination every 4 weeks during treatment period until complete response.

After complete response, follow-up carried every 3 months was extracted from files for at least 1 year.

\section{Statistical analysis:}

Data were collected, revised, coded and entered to the Statistical Package for Social Science (IBM SPSS) version 23. The quantitative data were presented as mean, standard deviations and ranges when parametric. Also, qualitative variables were presented as number and percentages. The compar- 
ison between groups regarding qualitative data was done by using Chi-square test. The comparison between two independent groups regarding quantitative data with parametric distribution was done by using Independent $t$-test. The confidence interval was set to $95 \%$ and the margin of error accepted was set to $5 \%$. So, the $p$-value was considered significant as the following: $p>0.05$ : Non significant (NS). $p<0.05$ : Significant (S). $p<0.01$ : Highly significant (HS).

\section{Results}

Table (1): Clinical characteristics of group (A).

\begin{tabular}{lll}
\hline & & Group A (No.=9) \\
\hline Age: & Mean \pm SD & $0.88 \pm 0.55$ year \\
& Range & $0.25-1.8$ year \\
Sex: & Males & $6(66.7 \%)$ \\
& Females & $3(33.3 \%)$ \\
Complaint: & Brother of RB & $1(11.1 \%)$ \\
& Leucocoria & $5(55.6 \%)$ \\
& Squint & $3(33.3 \%)$ \\
Family history : & Negative & $7(77.8 \%)$ \\
& Positive & $2(22.2 \%)$ \\
\hline
\end{tabular}

This table shows that age of presentation of retinoblastoma patients in group $(\mathrm{A})$ patients was at range of 3 to 21 months, with average age of 10.56 months with standard deviation \pm 6.6 months. Percentage of positive family history among group (A) was $22.2 \%, 2$ of 9 group (A) patients.

Table (2): Group (A) fully dilated fundus examination details.

\begin{tabular}{lll}
\hline & & Group A (No.=9) \\
\hline Tumor size: & $\leq 3 \mathrm{~mm}$ & $9(100.0 \%)$ \\
& $>3 \mathrm{~mm}$ & $0(0.0 \%)$ \\
Near OD of foveola: $:$ & No & $9(100.0 \%)$ \\
& Yes & $0(0.0 \%)$ \\
\hline
\end{tabular}

This table shows that tumor size was $3 \mathrm{~mm}$ or less and was located at least $3 \mathrm{~mm}$ from the foveola and $1.5 \mathrm{~mm}$ from OD in all group (A) patients.

Table (3): First line treatment options of group (A) patients.

\begin{tabular}{llc}
\hline & & Group A (No.=9) \\
\hline Chemotherapy: & No & $2(22.2 \%)$ \\
& Yes & $7(77.8 \%)$ \\
Chemotherapy cycles: & Mean \pm SD & $7.86 \pm 2.85$ \\
& Range & $6-12$ \\
Laser: & No & $0(0.0 \%)$ \\
& Yes & $9(100.0 \%)$ \\
Laser sessions: & Mean \pm SD & $6.44 \pm 2.35$ \\
& Range & $3-12$ \\
\hline
\end{tabular}

These table and figure show that $77.8 \%$ of group (A) Pts. had received systemic chemotherapy (7 out of 9) and $100 \%$ underwent laser thermotherapy. Average count of chemotherapy cycles was 7.86 with SD \pm 2.85 (range 6-12). Average number of laser sessions was 6 with SD \pm 2.35 (range 312).

Table (4): Primary outcome of group (A).

\begin{tabular}{llll}
\hline & & \multicolumn{2}{l}{ Group A (No.=9) } \\
\hline Regression: & No & 0 & $0.0 \%$ \\
& Yes & 9 & $100.0 \%$ \\
Continue chemotherapy: & No & 9 & $100.0 \%$ \\
& Yes & 0 & $0.0 \%$ \\
Add laser sessions: & No & 9 & $100.0 \%$ \\
& Yes & 0 & $0.0 \%$ \\
EBR: & No & 9 & $100.0 \%$ \\
& Yes & 0 & $0.0 \%$ \\
Enucleation: & No & 9 & $100.0 \%$ \\
& Yes & 0 & $0.0 \%$ \\
\hline
\end{tabular}

These table and figure show that $100 \%$ of group (A) Pts. Showed tumor regression (9 out of 9). There was no need to continue chemotherapy or add laser sessions or EBR or enucleation.

Table (5): Final outcome of group (A).

\begin{tabular}{ll}
\hline & Group A (No.=9) \\
\hline Observation time or period (months): & \\
Mean \pm SD & $30.11 \pm 7.74$ months \\
Range & $15-41$ months \\
Final outcome: & \\
Complete regression & $8(88.9 \%)$ \\
Enucleation & $0(0.0 \%)$ \\
Dead & $1(11.1 \%)$ \\
\hline
\end{tabular}

This table shows that average period of observation of group (A) patients was 30.11 months with SD \pm 7.74 . Complete repression had been achieved in $90 \%$ of Pts. (8 out of 9). One Pt. died of pneumonia (no available data if it was related to chemotherapy or not) during follow-up.

Table (6): Clinical characteristics of group (B).

\begin{tabular}{lll}
\hline & & Group B (No.=21) \\
\hline Age: & Mean \pm SD & $1.17 \pm 0.74$ year \\
& Range & $0.1-3$ year \\
Sex: & Males & $11(52.38 \%)$ \\
\multirow{4}{*}{ Complaint: } & Females & $10(47.62 \%)$ \\
& Leucocoria & $19(90.5 \%)$ \\
& Mass & $1(4.8 \%)$ \\
Family history: & Negaint & $1(4.8 \%)$ \\
& Positive & $19(90.5 \%)$ \\
\hline
\end{tabular}


This table shows that age of presentation of retinoblastoma patients in group (B) patients was at range of 1 month to 3 years, with average age of 1.17 year with standard deviation \pm 0.74 year. Percentage of positive family history among group (B) was $9.5 \%, 2$ of 21 group (B) patients.

Table (7): Group (B) fully dilated fundus examination details.

\begin{tabular}{llc}
\hline & & Group B (No.=21) \\
\hline Tumor size: & $\leq 3 \mathrm{~mm}$ & $4(19.0 \%)$ \\
& $>3 \mathrm{~mm}$ & $17(81.0 \%)$ \\
Near OD of foveola: $:$ & No & $8(38.1 \%)$ \\
& Yes & $13(61.9 \%)$ \\
\hline
\end{tabular}

This table shows that tumor size was $3 \mathrm{~mm}$ or less in 4Pt. (19\%) and more than $3 \mathrm{~mm}$ in $17 \mathrm{Pt}$. $(81 \%)$. Tumor was located at least $3 \mathrm{~mm}$ from the foveola and $1.5 \mathrm{~mm}$ from OD in $8 \mathrm{Pt}$. (38.1\%) and near OD or foveola in 13Pt. (61.9\%).

Table (8): First line treatment options of group (B) patients.

\begin{tabular}{lll}
\hline & & Group B (No.=21) \\
\hline Chemotherapy: & No & $1(4.8 \%)$ \\
& Yes & $20(95.2 \%)$ \\
Chemotherapy cycles: & Mean \pm SD & $7.95 \pm 2.24$ \\
& Range & $6-12$ \\
Laser: & No & $5(23.8 \%)$ \\
& Yes & $16(76.2 \%)$ \\
Laser sessions: & Mean \pm SD & $5.75 \pm 0.68$ \\
& Range & $4-6$ \\
\hline
\end{tabular}

These table and figure show that $95.2 \%$ of group (B) Pts. had received systemic chemotherapy (20 out of 21 ) and $76.2 \%$ underwent laser thermotherapy. Average count of chemotherapy cycles was 7.95 with SD \pm 2.24 (range 6-12). Average number of laser sessions was 5.75 with SD \pm 0.68 (range 4-6).
Table (9): Primary outcome of group (B)

\begin{tabular}{llll}
\hline & & \multicolumn{2}{c}{ Group A } \\
\cline { 3 - 4 } & & No. & \multicolumn{1}{c}{$\%$} \\
\hline Regression: & No & 3 & $14.3 \%$ \\
& Yes & 18 & $85.7 \%$ \\
Continue chemotherapy: & No & 19 & $90.5 \%$ \\
& Yes & 2 & $9.5 \%$ \\
Add laser sessions: & No & 20 & $95.2 \%$ \\
& Yes & 1 & $4.8 \%$ \\
EBR: & No & 19 & $90.5 \%$ \\
& Yes & 2 & $9.5 \%$ \\
Enucleation: & No & 19 & $90.5 \%$ \\
& Yes & 2 & $9.5 \%$ \\
\hline
\end{tabular}

These table and figure show that $85.7 \%$ of group (B) Pts. Showed tumor regression (18 out of 21 ) and $14.3 \%$ showed no primary response (3 out of 21). Chemotherapy cycles was continued in $9.5 \%$ of Pts. (2 out of 21). Laser sessions was added in $4.8 \%$ of Pts. ( 1 out of 21 ). EBR was needed in $9.5 \%$ of Pts. (2 out of 21). Enucleation also was needed in $9.5 \%$ of Pts. (2 out of 21 ).

Table (10): Final outcome of group (B).

\begin{tabular}{ll}
\hline & Group B (No.=21) \\
\hline Observation time or period (months): & \\
$\quad$ Mean \pm SD & $32.43 \pm 6.55$ months \\
Range & $24-55$ months \\
Final outcome: & \\
$\quad$ Complete regression & $19(90.5 \%)$ \\
$\quad$ Enucleation & $2(9.5 \%)$ \\
\hline
\end{tabular}

This table shows that average period of observation of group (B) patients was 32.43 months with SD \pm 6.55 . Complete regression had been achieved in $90.5 \%$ of Pts. (19 out of 21). 9.5\% of cases ( 2 out of 21 ) ended with enucleation.

Table (11): Follow-up and final outcome comparison between group (A) and group (B) of our patients.

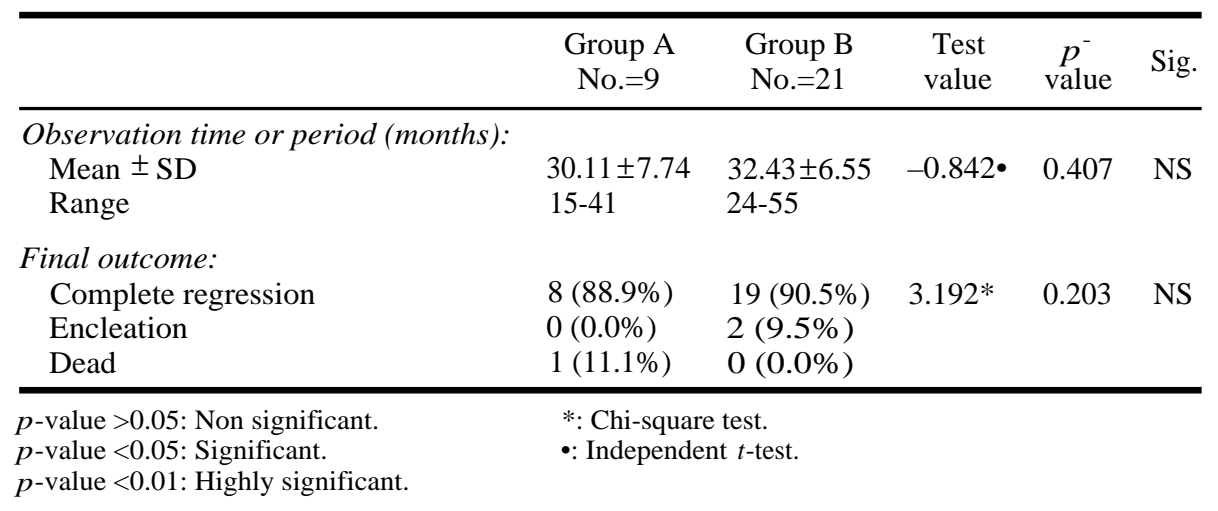

This table shows that no significant difference had been found in observation period nor final outcome between group (A) and group (B) patients. $88.9 \%$ of group (A) patients (8 out of 9 ) had com- 
plete regression and only one patient $11.1 \%$ (1 out of 9) died from pneumonia. 90.5\% of group (B) patients (19 out of 21) had complete regression and only two patients $9.5 \%$ (2 out of 21) had eye enucleated.

\section{Discussion}

Managing early retinoblastoma (group A and B ICRB) has the importance that we can achieve eye salvage with the recent favorable easy line of treatment consisting of chemoreduction mainly with or without focal therapy.

The ICRB (international classification of intraocular retinoblastoma) was designed to simplify retinoblastoma classification and to predict treatment success with current methods, specifically CRD (chemoreduction). This classification was not intended to predict life prognosis or visual outcome. It was intended to predict globe outcome, specifically, avoidance probability of enucleation and EBRT after CRD. In this study, we have noticed that patients within groups A and B had a considerable chance for globe salvage and avoidance of EBRT [8-10].

According to our study: Complete tumor regression had occurred in $90 \%$ of all group A and B patients following treatment with systemic chemotherapy plus focal laser thermotherapy. Enucleation was needed in $6.7 \%$ of all patients. Group A only patients had a $90 \%$ percentage of complete tumor regression, with only one patient died from pneumonia (one out of 30). Group B only patients had a $90.5 \%$ percentage of complete tumor regression, with only two patients had needed enucleation (2 out of 30 ).

EBR was needed in $6.7 \%$ of all patients. Age at presentation mean was 1.09 year with range (0.1-3). Regarding presenting symptoms, $80 \%$ of patients presented with leukocoria and $13.3 \%$ with squint. Family history was negative in $86.7 \%$ and positive in $13.3 \%$.

So our study results support the findings from previous studies on retinoblastoma; Shields et al. (2008), found the success of chemoreduction protocol in $100 \%$ of 23 group A patients and $93 \%$ of 96 group B patients.

Novetsky [10], found $16 \%$ enucleation percentage in 10 group A patients +53 group B patients who received single-agent intravenous carboplatin. Age range was (0.03-2.5 year).

Friedman [20], found that systemic neoadjuvant chemotherapy (Vincristine and Carboplatin (VC), accompanied by local ophthalmic therapies such as cryotherapy, diode laser thermotherapy, or brachytherapy, as required) for 21 Group B intraocular retinoblastoma patients achieved eye salvage percentage of $85 \%$, enucleation percentage was $15 \%$ and EBR percentage was $10 \%$.

Lumbroso [21], describe the efficacy of conservative management of retinoblastoma by an association of conservative ocular therapies and chemothermotherapy (carboplatin) and found that eye salvage was $100 \%$ in 16 group A patients, $94.59 \%$ in 37 group B patients and EBR followed by enucleation was needed in $5.41 \%$ of group B patients.

Friedman [22], found that chemoreduction (vincristine, etoposide, and Carboplatin) with local ophthalmic therapy for early intraocular retinoblastoma (Reese-Ellsworth groups 1 and 2) resulted in avoidance of EBR and Enucleation in $100 \%$ of 18 patients.

\section{In comparison with our study:}

Zage [2], found that the vision salvage rate without EBRT for 22 eyes with ICRB groups A and $\mathrm{B}$ tumors treated with chemoreduction (carboplatin and etoposide) plus focal retinal therapy was $77.3 \%, 100 \%$ for 7 group A patients alone and $66.7 \%$ for 15 group B patients alone. Enucleation was needed in 5 out of 15 group B patients. The mean age at diagnosis was 0.975 year (range 0.15.3 year).

Factors that may have influenced our results and conclusions:

Filing system, all our data retrieved from patients records, so any inaccurate details could change results specially the data of tumor size and location as it disrupts group classification of patients in study based on international classification of intraocular retinoblastoma like our study.

Study period, our study results depended on at least one-year period of non-progressed tumor, more post-treatment follow-up time could lead to more assured results of re-progressed tumors.

\section{Conclusion:}

Our conclusion is that early retinoblastoma patients (group A and B ICRB) treated by systemic chemotherapy in conjunction with local control have resulted in ocular salvage rates exceeding $90 \%$ for early intraocular disease.

\section{References}

1- YUN J., LI Y., XU C.T. and PAN B.R.: Epidemiology and $\mathrm{Rb} 1$ gene of retinoblastoma. International Journal of Ophthalmology, 4 (1): 103-9, 2011. 
2- ZAGE P.E., REITMAN A.J., SESHADRI R., WEINSTEIN J.L., METS M.B., ZEID J.L., et al.: Outcomes of a twodrug chemotherapy regimen for intraocular retinoblastoma. Pediatric blood \& cancer, 50 (3): 567-72, 2008.

3- CASTERA L., SABBAGH A., DEHAINAULT C., MICHAUX D., MANSUET-LUPO A., PATILLON B., et al.: MDM2 as a modifier gene in retinoblastoma. Journal of the National Cancer Institute, 102 (23): 1805-8, 2010.

4- PALAZZI M., ABRAMSON D.H. and ELLSWORTH R.M.: Endophytic vs exophytic unilateral retinoblastoma: Is there any real difference? Journal of pediatric ophthalmology and strabismus, 27 (5): 255-8, 1990.

5- SHIELDS C.L., GHASSEMI F., TUNCER S., THANGAPPAN A. and SHIELDS J.A.: Clinical spectrum of diffuse infiltrating retinoblastoma in 34 consecutive eyes. Ophthalmology, 115 (12): 2253-8, 2008.

6- ABRAMSON D.H., FRANK C.M., SUSMAN M., WHALEN M.P., DUNKEL I.J. and BOYD N.W.: Presenting signs of retinoblastoma. The Journal of pediatrics, 132 (3 Pt 1): 505-8, 1998a

7- APUSHKIN M.A., APUSHKIN M.A., SHAPIRO M.J. and MAFEE M.F.: Retinoblastoma and simulating lesions: Role of imaging. Neuroimaging Clin. N. Am., 15 (1): 4967, 2005.

8- LINN MURPHREE A.: Intraocular Retinoblastoma: The Case for a New Group Classification. Ophthalmology Clinics, 18 (1): 41-53, 2005a.

9- SHIELDS C.L., MASHAYEKHI A., AU AK, CZYZ C., LEAHEY A., MEADOWS A.T., et al.: The International Classification of Retinoblastoma predicts chemoreduction success. Ophthalmology, 113 (12): 2276-80, $2006 \mathrm{a}$.

10- NOVETSKY D.E., ABRAMSON D.H., KIM J.W. and DUNKEL I.J.: Published international classification of retinoblastoma (ICRB) definitions contain inconsistencies-an analysis of impact. Ophthalmic genetics, 30 (1): 404, 2009.

11- CHINTAGUMPALA M., CHEVEZ-BARRIOS P., PAYSSE E.A., PLON S.E. and HURWITZ R.: Retinoblastoma: Review of current management. The oncologist, 12 (10): 1237-46, 2007.

12- ABRAMSON D.H., FABIUS A.W., ISSA R., FRANCIS J.H., MARR B.P., DUNKEL I.J., et al.: Advanced Unilateral Retinoblastoma: The Impact of Ophthalmic Artery Chemosurgery on Enucleation Rate and Patient Survival at MSKCC. PloS one, 10 (12): e0145436, 2015.
13- TAMBOLI D., TOPHAM A., SINGH N. and SINGH A.D. Retinoblastoma: A SEER Dataset Evaluation for Treatment Patterns, Survival, and Second Malignant Neoplasms. American journal of ophthalmology, 160 (5): 953-8, 2015.

14- EL-BARBARY M.M., SAID A.M.A. and EL-AWADY M.K.: Study of Management of Retinoblastoma with Vitreous Seeds (Retrospective Study) Med. J. Cairo Univ., 86 (1): 43-8, 2018

15- ROTHSCHILD P.R., LEVY D., SAVIGNONI A., LUMBROSO-LE ROUIC L., AERTS I., GAUTHIERVILLARS M., et al.: Familial retinoblastoma: Fundus screening schedule impact and guideline proposal. A retrospective study. Eye (London, England), 25 (12): 1555-61, 2011.

16- SKALET A.H., GOMBOS D.S., GALLIE B.L., KIM J.W., SHIELDS C.L., MARR B.P., et al.: Screening Children at Risk for Retinoblastoma: Consensus Report from the American Association of Ophthalmic Oncologists and Pathologists. Ophthalmology, 125 (3): 453-8, 2018.

17- LINABERY A.M. and ROSS J.A.: Childhood and adolescent cancer survival in the US by race and ethnicity for the diagnostic period 1975-1999. Cancer, 113 (9): 257596, 2008.

18- FRIEDMAN D.N., CHOU J.F., OEFFINGER K.C., KLEINERMAN R.A., FORD J.S., SKLAR C.A., et al.: Chronic medical conditions in adult survivors of retinoblastoma: Results of the Retinoblastoma Survivor Study. Cancer, 122 (5): 773-81, 2016.

19- SINGH A.D., SHIELDS C.L. and SHIELDS J.A.: Prognostic factors in retinoblastoma. Journal of pediatric ophthalmology and strabismus, 37 (3): 134-41; quiz 689, 2000 .

20- FRIEDMAN D.L., KRAILO M., VILLALUNA D., GOMBOS D., LANGHOLZ B., JUBRAN R., et al.: Systemic neoadjuvant chemotherapy for Group B intraocular retinoblastoma (ARET0331): A report from the Children's Oncology Group. Pediatric blood \& cancer, 64 (7), 2017.

21- LUMBROSO-LE ROUIC L., AERTS I., LEVY-GABRIEL C., DENDALE R., SASTRE X., ESTEVE M., et al.: Conservative treatments of intraocular retinoblastoma. Ophthalmology, 115 (8): 1405-10, 10.e1-2, 2008.

22- FRIEDMAN D.L., HIMELSTEIN B., SHIELDS C.L., SHIELDS J.A., NEEDLE M., MILLER D., et al.: Chemoreduction and local ophthalmic therapy for intraocular retinoblastoma. Journal of clinical oncology: Official journal of the American Society of Clinical Oncology, 18 (1): $12-7,2000$ 


\section{دراسة إرتجاعية لمناظرة مجموعة (آ) و (ب) من الورم الآرومى الشبكى}

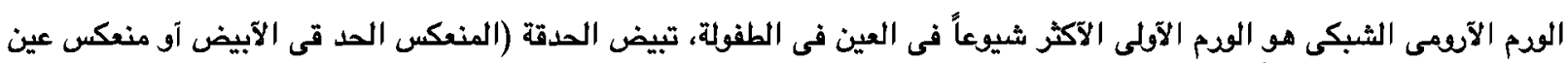

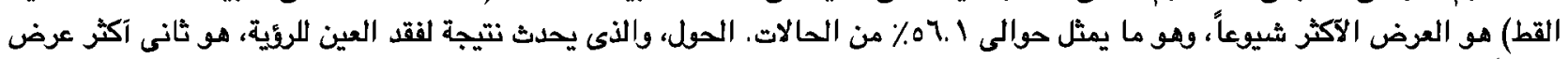

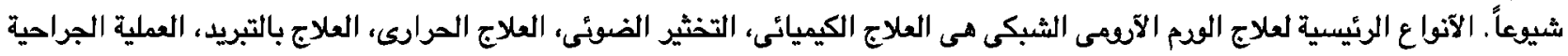

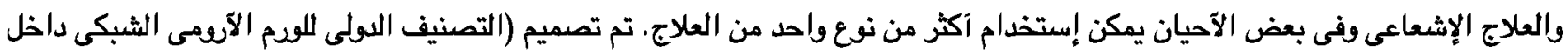

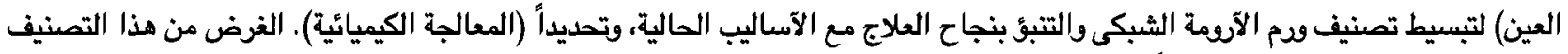

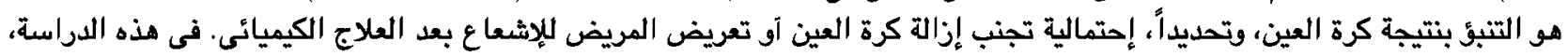

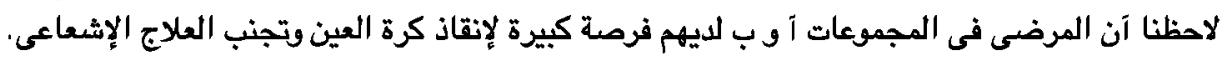

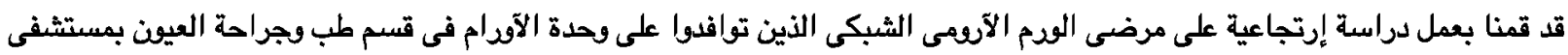

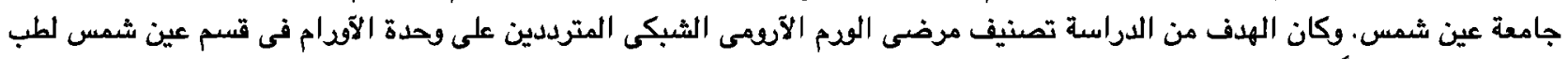

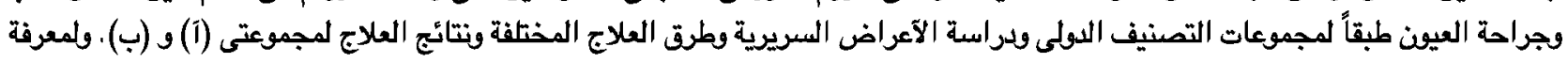

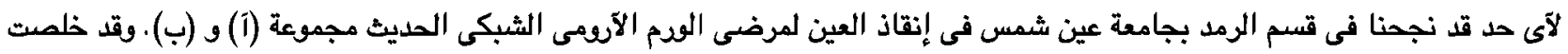

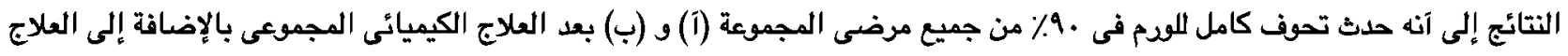

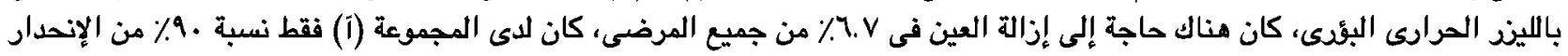

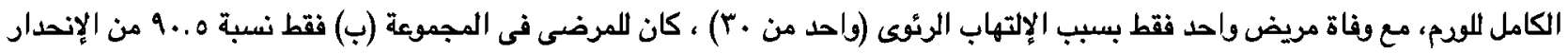

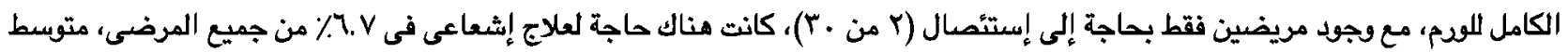

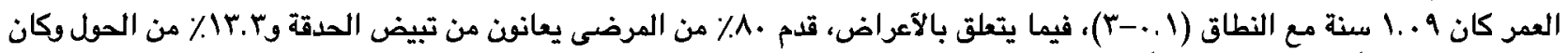

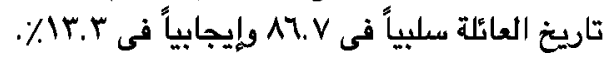

